\title{
Early lymphocyte recovery as a predictor of outcome, including relapse, after hematopoietic stem cell transplantation
}

\author{
Juliane Morando \\ Sérgio Costa Fortier \\ Ricardo Pasquini \\ José Zanis Neto \\ Carmem Maria Sales Bonfim
}

Universidade Federal do Paraná - UFPR, Curitiba, PR, Brazil
Conflict-of-interest disclosure: The authors declare no competing financial interest

Submitted: 4/11/2012

Accepted: 6/29/2012

\section{Corresponding author:}

Juliane Morando

Serviço de Transplante de Medula Óssea da Universidade Federal do Paraná - UFPR

Rua Amintas de Barros, 871/204

80045-155 Curitiba, PR, Brazil

julimorando@terra.com.br

www.rbhh.org or www.scielo.br/rbhh
Background: Despite advances in the treatment of acute leukemia, many patients need to undergo hematopoietic stem cell transplantation. Recent studies show that early lymphocyte recovery may be a predictor of relapse and survival in these patients.

Objective: To analyze the influence of lymphocyte recovery on Days +30 and +100 post-transplant on the occurrence of relapse and survival.

Methods: A descriptive, retrospective study was performed of 137 under 21-year-old patients who were submitted to hematopoietic stemcell transplantationfor acuteleukemiabetween 1995 and 2008. Alymphocyte count $<0.3 \times 10^{9} /$ L on Day +30 post-transplant was considered to be inadequate lymphocyte recovery and counts $\geq 0.3 \times 10^{9} / \mathrm{L}$ were considered adequate. Lymphocyte recovery was also analyzed on Day +100 with $<0.75 \times 10^{9} / \mathrm{L}$ and $\leq 0.75 \times 10^{9} / \mathrm{L}$ being considered inadequate and adequate lymphocyte recovery, respectively.

Results: There was no significant difference in the occurrence of relapse between patients with inadequate and adequate lymphocyte recovery on Day +30 post-transplant. However, the transplant-related mortality was significantly higher in patients with inadequate recovery on Day +30 . Patients with inadequate lymphocyte recovery on Day +30 had worse overall survival and relapse-free survival than patients with adequate recovery. There was no significant difference in the occurrence of infections and acute or chronic graft-versus-host disease. Patients with inadequate lymphocyte recovery on Day +100 had worse overall survival and relapse-free survival and a higher cumulative incidence of relapse.

Conclusion: The evaluation of lymphocyte recovery on Day +30 is not a good predictor of relapse after transplant however patients with inadequate lymphocyte recovery had worse overall survival and relapse-free survival. Inadequate lymphocyte recovery on Day +100 is correlated with higher cumulative relapse as well as lower overall survival and relapse-free survival.

Keywords: Leukemia; Hematopoietic stem cell transplantation; Lymphocyte count

\section{Introduction}

Acute leukemia is the most common neoplasm in children; it is responsible for $25-30 \%$ of cancer cases in under 15-year-old children ${ }^{(1)}$. Despite the advances in treatment and supportive care, disease-free survival at five years remains between 35 and $60 \%{ }^{(1,2)}$. For patients with high-risk disease and for those who present disease relapse, hematopoietic stem cell transplantation (HSCT) is the curative alternative $\mathrm{e}^{(3,4)}$.

After HSCT, the total lymphocyte count returns to normal in approximately 3 months. However, the normal amount of $\mathrm{T}$ and $\mathrm{B}$ cells, in particular $\mathrm{T} \mathrm{CD} 4^{+}$cells, is only reached at around 12 months after $\mathrm{HSCT}^{(5)}$.

In the early period after HSCT, the number of natural killer (NK) cells rises rapidly, and these represent the majority of mononuclear cells in the peripheral blood. NK cells are responsible for the early graft-versus-leukemia effect and slow recovery is related to increased risk of disease relapse ${ }^{(6)}$.

Some studies have shown the importance of early lymphocyte recovery (LR) after HSCT and its correlation with survival, lower relapse rates and lower transplant-related mortality (TRM) ${ }^{(7-9)}$.

The objective of this study was to evaluate the importance of the lymphocyte count on Days +30 and +100 after transplant as predictors of relapse and survival in pediatric patients submitted to HSCT for acute leukemia.

\section{Methods}

Patients

A total of 141 under 21-year-old patients with acute leukemia were submitted to HSCT between April 1995 and December 2008. Of these, 137 patients survived over 30 days and were included in this analysis. The patients' ages varied from 1 to 20 years with a median of 9 
years. Forty-eight patients (35\%) were female and $89(65 \%)$ were male. Eighty-one patients $(59 \%)$ had acute lymphoblastic leukemia (ALL) and 56 patients (41\%) had acute myeloid leukemia (AML). Patients transplanted in first and second clinical remission were considered as having early disease $(n=82 ; 60 \%)$ and those with disease in third remission or higher, refractory disease or relapse, were considered as having advanced disease $(n=55 ; 40 \%)$.

\section{Donors, stem cell source and conditioning regimens}

Seventy-one patients $(52 \%)$ received transplants from related donors and 66 patients $(48 \%)$ had non-related donors; 103 patients received bone marrow cells (75\%) and 34 umbilical cord blood $(25 \%)$. The conditioning regimens were busulfan + cyclophosphamide $(\mathrm{Bu} / \mathrm{CY} ; \mathrm{n}=34 ; 25 \%)$, total body irradiation + cyclophosphamide $(\mathrm{TBI} / \mathrm{CY} ; \mathrm{n}=69 ; 50 \%), \mathrm{TBI} / \mathrm{CY}$ + antithymocyte immunoglobulin (TBI/CY/ATG; $\mathrm{n}=33 ; 24 \%$ ) and others (fludarabine/CY and CY/ATG; $\mathrm{n}=2 ; 1 \%$ ). Prophylaxis of graft-versus-host disease (GVHD) was by methotrexate + cyclosporine (MTX/CsA; $\mathrm{n}=98 ; 71 \%)$, cyclosporine + corticosteroid (CsA + CTC; $\mathrm{n}=25 ; 18 \%$ ), cyclosporine only $(\mathrm{CsA} ; \mathrm{n}=9 ; 7 \%)$ and cyclosporine + MTX + corticosteroid $(\mathrm{CsA} / \mathrm{MTX} / \mathrm{CTC} ; \mathrm{n}=5 ; 4 \%)$.

\section{Definitions}

LR was evaluated by the total lymphocyte count in peripheral blood on Days +30 and +100 after HSCT. Patients with lymphocyte counts (LC) lower than $0.3 \times 10^{9} / \mathrm{L}$ on Day +30 and lower than $0.75 \times 10^{9} / \mathrm{L}$ on Day +100 were considered as having inadequate LR. The cutoff value of $0.3 \times 10^{9} / \mathrm{L}$ was chosen based on published studies ${ }^{(8,10)}$ and the cutoff value of $0.75 \times 10^{9} / \mathrm{L}$ was chosen as it was the median lymphocyte count on Day +100 .

HLA compatibility was evaluated based on the characteristics of the class I and II antigens of the major histocompatibility complex in A, B (low resolution) and DRB1 (high resolution) loci. Patients and donors were considered entirely compatible when the antigens were the same in all six loci (6/6 compatibility).

Engraftment was confirmed by the cell count in the peripheral blood (neutrophils: absolute count over $0.5 \times 10^{9} / \mathrm{L}$ for three consecutive days; Platelets: absolute count higher than $20 \times 10^{9} / \mathrm{L}$ for three consecutive days without the need of transfusion for seven days).

Only patients with neutrophil engraftment were evaluated for the occurrence of acute graft-versus-host disease (GVHD) and only patients who survived with engraftment for more than 100 days were evaluated for chronic GVHD.

Acute GVHD was defined according to previously published clinical and laboratorial criteria $^{(11)}$ and classified as Stage I to IV. Chronic GVHD was classified as limited or extensive according to the classification criteria proposed in $1980^{(12)}$.

The occurrence of death in the first 100 days after HSCT due to any cause except relapse of the disease was considered transplant-related mortality (TRM).

The Overall Survival (OS) was calculated from the day of HSCT until death by any cause and the relapse-free survival (RFS) was calculated from the day of HSCT until disease relapse or death by any cause, whichever came first.

\section{Statistical analysis}

The Kaplan Meier method was used to analyze the OS and RFS. The log rank test was used for univariate analysis and Cox regression for multivariate analysis with variables that presented a p-value $<0.2$ in the univariate analysis being included. Death without engraftment and the death in remission were used as competitive risk factors in the evaluation of the cumulative incidences of engraftment and relapse. Mortality due to relapse was used as a competitive risk factor in the analysis of the cumulative incidence of TRM. The Gray method was used to compare the cumulative incidence curves. The multinomial logistic regression was used in the analysis of the factors that influenced LR on Day +30 and on Day +100 .

A level of significance of $5 \%$ (p-value $<0.05)$ and a power of $80 \%$ were used in the analysis. The SPSS (Statistical Package for the Social Sciences) and STATA 11 programs were used to perform statistical analysis.

\section{Results}

\section{Patient characteristics}

The characteristics of patients according to LR are summarized in Table 1.

\begin{tabular}{|c|c|c|c|}
\hline & $\begin{array}{c}\text { Lymphocyte } \\
\text { recovery } \\
\text { Day }+\mathbf{3 0} \\
<0.3 \times 10^{9} / \mathrm{L} \\
\mathrm{n}(\%)\end{array}$ & $\begin{array}{c}\text { Lymphocyte } \\
\text { recovery } \\
\text { Day }+\mathbf{3 0} \\
\geq 0.3 \times 10^{9} / \mathrm{L} \\
\mathrm{n}(\%)\end{array}$ & $\begin{array}{c}\text { p-value* } \\
\text { chi-square } \\
\text { test }\end{array}$ \\
\hline Gender & & & NS \\
\hline Female & $17(31)$ & $31(38)$ & \\
\hline Male & $38(59)$ & $51(62)$ & \\
\hline Age & & & 0.034 \\
\hline$\geq 9$ year old & $24(44)$ & $52(63)$ & \\
\hline$<9$ year old & $31(56)$ & $30(37)$ & \\
\hline Diagnosis & & & NS \\
\hline ALL & $34(62)$ & $47(57)$ & \\
\hline AML & $21(38)$ & $35(43)$ & \\
\hline Disease status & & & 0.007 \\
\hline Early disease & $30(54)$ & $26(32)$ & \\
\hline Advanced disease & $25(46)$ & $56(68)$ & \\
\hline Stem cell source & & & 0.008 \\
\hline Cord blood & $21(38)$ & $13(16)$ & \\
\hline Bone marrow & $34(62)$ & $69(84)$ & \\
\hline Donor $x$ compatibility & & & NS \\
\hline Related compatible & $20(36)$ & $43(52)$ & \\
\hline $\begin{array}{l}\text { Related with } \\
\text { incompatibilities }\end{array}$ & $2(1)$ & $6(7)$ & \\
\hline Non-related compatible & $11(20)$ & $17(21)$ & \\
\hline $\begin{array}{l}\text { Non-related with } \\
\text { incompatibilities }\end{array}$ & $22(43)$ & $16(20)$ & \\
\hline
\end{tabular}

ALL: acute lymphocyte leukemia; AML: myeloid leukemia; NS: non-significant 


\section{Engraftment and GVHD analysis}

Complete engraftment was achieved by 117 patients (85\%). Of the others, seven patients had only partial engraftment (5\%) and 13 patients had primary graft failure $(10 \%)$.

One hundred and twenty-four patients had neutrophilic engraftment and were included in the acute GVHD analysis and of these, 56 patients (41\%) had acute GVHD, $30(53 \%)$ at Stage III-IV. Chronic GVHD was evaluated in 112 patients that survived over 100 days with engraftment; 25 patients (22\%) presented chronic GVHD with extensive disease in 14 patients (56\%).

\section{Global and relapse-free survival analysis}

The 3-year OS was 47\%, with a median of 1169 days (range: 181-4760 days), as demonstrated in Figure 1. In the multivariate analysis, the factors related to worse OS were: inadequate LR on Days +30 and +100 and advanced disease at the time of HSCT (Table 2).

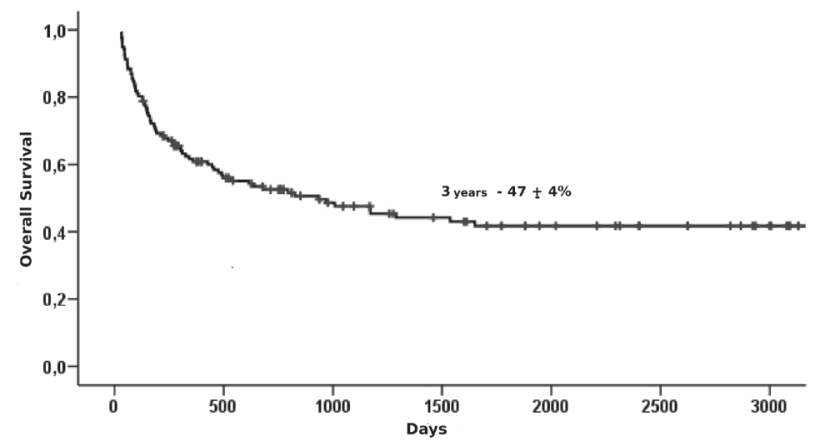

Figure 1 - Three-year overall survival

Table 2 - Nominal Logistic regression

\begin{tabular}{lcr}
\hline & $\begin{array}{c}\text { Lymphocyte recovery } \\
\text { Day +30 } \\
\text { p-value }(\mathrm{OR} ; 95 \% \text { CI) }\end{array}$ & $\begin{array}{c}\text { Lymphocyte recovery } \\
\text { Day +100 } \\
\text { p-value }(\mathrm{OR} ; 95 \% \mathrm{CI})\end{array}$ \\
\hline Age ( $\leq 9$ vs. $>$ 9 year old) & $0.01(2.23 ; 1.11-4.49)$ & $0.3(0.64 ; 0.28-1.49)$ \\
Diagnosis (ALL vs. AML) & $0.59(1.2 ; 0.6-2.42)$ & $0.01(3.24 ; 1.12-11.6)$ \\
Donor (related vs. non-related) & $0.03(2.22 ; 1.10-4.47)$ & $0.04(2.10 ; 1.08-4.79)$ \\
Disease status (early vs. advanced) & $0.02(2.58 ; 1.27-5.23)$ & $0.6(1.18 ; 0.51-2.73)$ \\
Stem cell source (CB vs. BM) & $0.008(0.30 ; 0.13-0.68)$ & $0.58(1.32 ; 0.47-3.71)$ \\
ATG use (Yes vs. no) & $0.62(1.12 ; 0.56-2.62)$ & $0.03(2.61 ; 1.06-7.06)$ \\
\hline
\end{tabular}

OR: Odds ratio; 95\% CI: 95\% confidence interval; ALL: acute lymphoblastic leukemia; AML: acute myeloid leukemia; CB: Cord blood; BM: bone marrow; ATG: antithymocyte globulin

p-value $<0.05$ denotes significant difference

The 3-year RFS was 39\% (Figure 2). After the transplant, 56 patients presented disease relapse, with a median time to relapse of 135 days (Range: $28-1273$ days). The cumulative incidence of relapse at 3 years was $45 \%$ as shown in Figure 3. In the multivariate analysis, the factors that negatively influenced RFS were an inadequate LR at Day +100 and advanced disease at the time of HSCT.

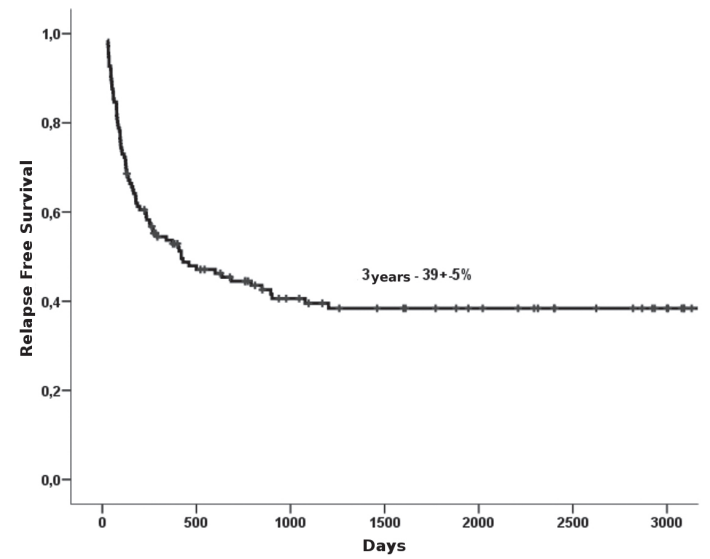

Figure 2 - Three-year relapse-free survival

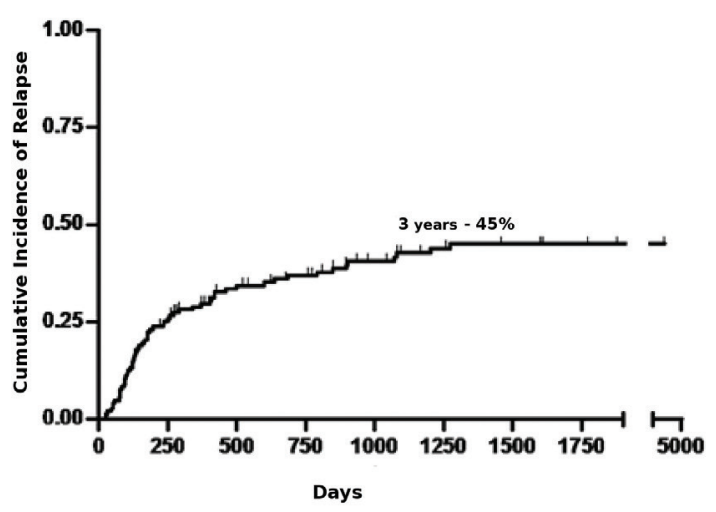

Figure 3 - Cumulative incidence of relapse

Seventy-three patients evolved to death in a median of 166 days after HSCT (range: 31-1650 days). The main causes of death were: disease relapse, infection and acute GVHD. Twenty patients evolved to death in the first 100 days after transplant with the cumulative incidence of TRM being 17\% (Figure 4). The causes of TRM were: infection (13 patients), acute GVHD (4 patients), veno-occlusive disease ( 2 patients) and engraftment failure (1 patient).

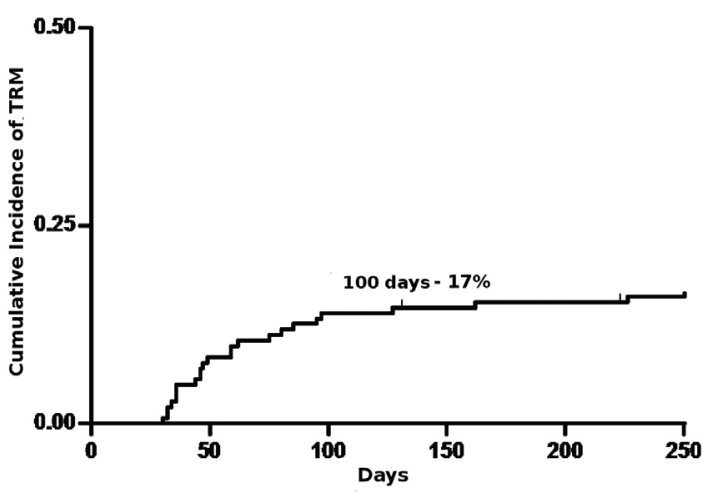

Figure 4 - Cumulative incidence of transplant-related mortality on Day +100 
Patients transplanted with early disease presented better OS $(61 \%$ vs. $27 \%$, p-value $=0.001)$ and RFS $(53 \%$ vs. $22 \%$, $\mathrm{p}$-value $=0,000)$ than patients transplanted with advanced disease.

$$
\text { Lymphocyte recovery on Day }+30
$$

The factors associated with inadequate LR on Day +30 were: HSCT from non-related donors ( $\mathrm{p}$-value $=0.03$ ), umbilical cord blood transplant ( $\mathrm{p}$-value $=0.008)$, age less than 9 years old ( $\mathrm{p}$-value $=0.01)$ and advanced disease at the time of HSCT $(\mathrm{p}$-value $=0.02)$ as shown in Table 2 . In the multivariate analysis none of the variables impacted the LR on Day +30 .

When the patients were stratified according to the donor type to perform the multivariate analysis, it was observed that in the group of transplanted patients with related donors, age less than 9 years old was the only factor with a negative influence on the LR on Day +30 , however, among the patients that received the transplant from non-related donors, none of the factors had significant influence on LR on Day +30 .

Patients with inadequate LR on Day +30 had worse OS and RFS (Figure 5).

The TRM was significantly higher in the group with inadequate LR on Day +30 (Figure 6).
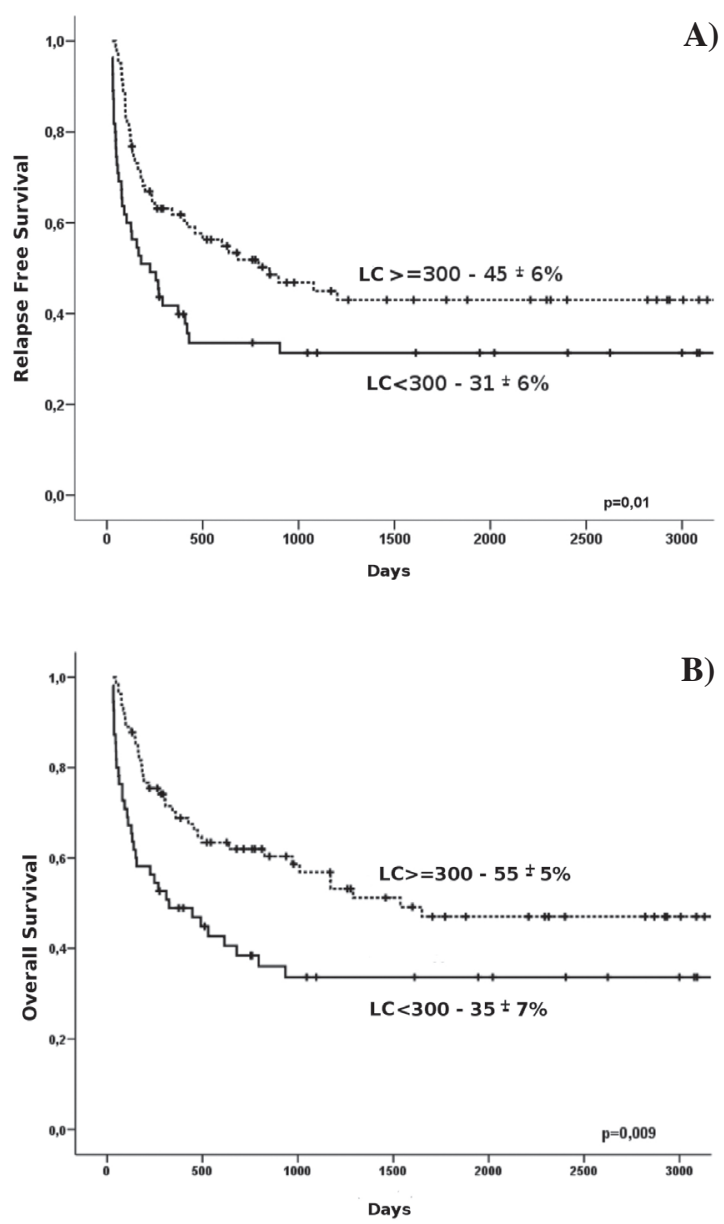

Figure 5 - Three-year A) overall survival and B) relapse-free survival based on lymphocyte recovery on Day +30

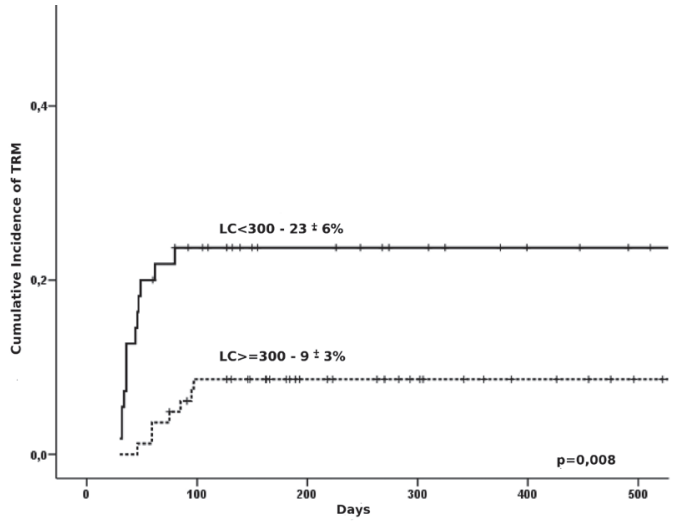

Figure 6 - Cumulative incidence of transplant-related mortality based on lymphocyte recovery on Day +30

A significant difference in the cumulative incidence of relapse was not observed between the groups of LR on Day +30 ( $p$-value $=0.4$ ).

Additionally, there were no significant differences in the occurrence of infections between the groups or in the incidence of acute or chronic GVHD.

\section{Lymphocyte recovery on Day +100}

One hundred and twelve patients that survived over 100 days after HSCT with complete engraftment were included in the analysis of LR on Day +100 . The characteristics of these patients are shown in Table 3 .

Table 3 - Patient characteristics according to lymphocyte recovery on Day +100

\begin{tabular}{|c|c|c|c|}
\hline & $\begin{array}{c}\text { Lymphocyte } \\
\text { recovery } \\
\text { Day }+\mathbf{1 0 0} \\
<0.75 \times 10^{9} / \mathrm{L} \\
\text { n }(\%)\end{array}$ & $\begin{array}{c}\text { Lymphocyte } \\
\text { recovery } \\
\text { Day }+\mathbf{1 0 0} \\
\geq 0.75 \times 10^{9} / \mathrm{L} \\
\mathrm{n}(\%)\end{array}$ & $\begin{array}{c}\text { p-value* } \\
\text { chi-square } \\
\text { test }\end{array}$ \\
\hline Gender & & & NS \\
\hline Female & $10(30)$ & $26(33)$ & \\
\hline Male & $23(70)$ & $53(67)$ & \\
\hline Age & & & NS \\
\hline$\geq 9$ year old & $21(64)$ & $42(53)$ & \\
\hline$<9$ year old & $12(36)$ & $37(47)$ & \\
\hline Diagnosis & & & 0.006 \\
\hline ALL & $25(76)$ & $38(48)$ & \\
\hline AML & $8(24)$ & $41(52)$ & \\
\hline Disease status & & & NS \\
\hline Early disease & $13(40)$ & $28(35)$ & \\
\hline Advanced disease & $20(60)$ & $51(65)$ & \\
\hline Stem cell source & & & NS \\
\hline Cord blood & $6(18)$ & $18(23)$ & \\
\hline Bone marrow & $27(82)$ & $61(77)$ & \\
\hline Donor $x$ compatibility & & & NS \\
\hline Related compatible & $12(36)$ & $42(53)$ & \\
\hline $\begin{array}{l}\text { Related with } \\
\text { incompatibilities }\end{array}$ & $2(6)$ & $6(8)$ & \\
\hline Non-related compatible & $11(33)$ & $18(23)$ & \\
\hline $\begin{array}{l}\text { Non-related with } \\
\text { incompatibilities }\end{array}$ & $8(15)$ & $13(16)$ & \\
\hline
\end{tabular}

ALL: acute lymphocyte leukemia; AML: myeloid leukemia; NS: non-significant 
The variables that negatively influenced the LR on Day +100 were: diagnosis of ALL ( $\mathrm{p}$-value $=0.01)$, transplant from non-related donor $(\mathrm{p}$-value $=0.04)$ and conditioning regimen containing antithymocyte immunoglobulin $(p$-value $=0.03)$ as shown in Table 2. In the multivariate analysis, none of the factors influenced LR on Day +100 .

When the patients were stratified according to donor type, it was observed that patients of non-related donors, had ALL as the only factor that negatively influenced the LR on Day +100 in the multivariate analysis, however, of the patients that received transplants from non-related donors, none of the factors significantly affected the LR on Day +100 .

Patients with inadequate LR on Day +100 presented statistically lower OS (p-value $=0.05$ ) and RFS ( -value $=0.01$; Figure 7). Furthermore, the cumulative incidence of relapse was significantly higher for the group with inadequate LR $(p$-value $=0.006)$ as shown in Figure 8.

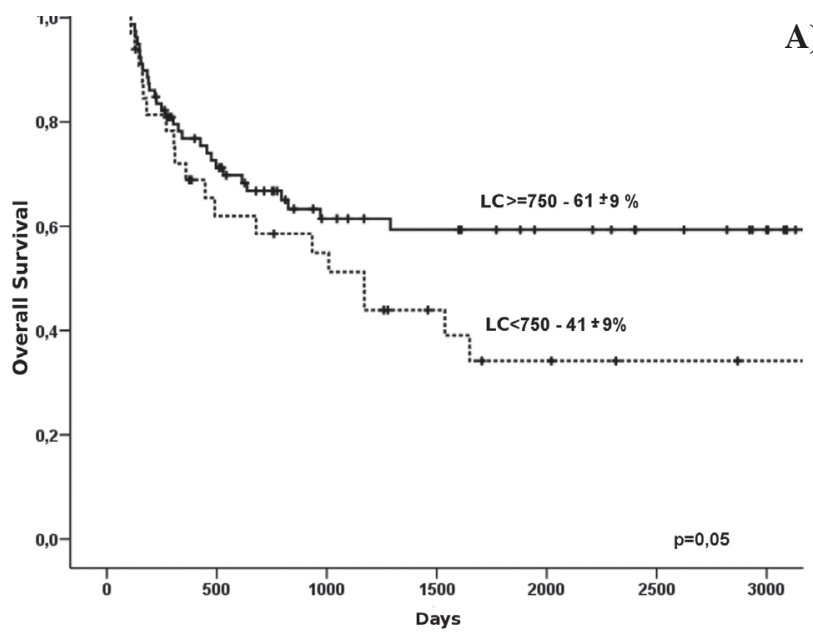

B)

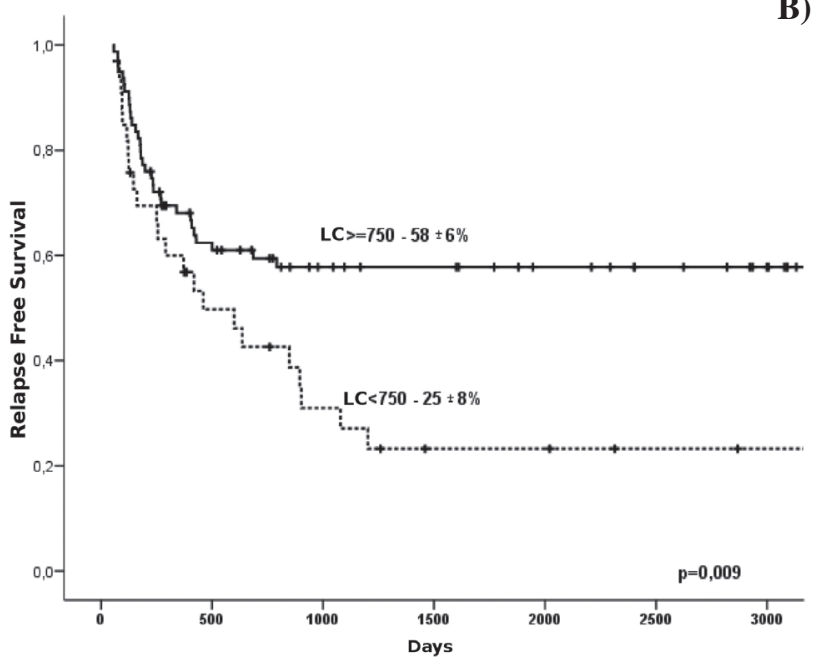

Figure 7 - Three-year A) overall survival and B) relapse-free survival based on lymphocyte recovery on Day +100

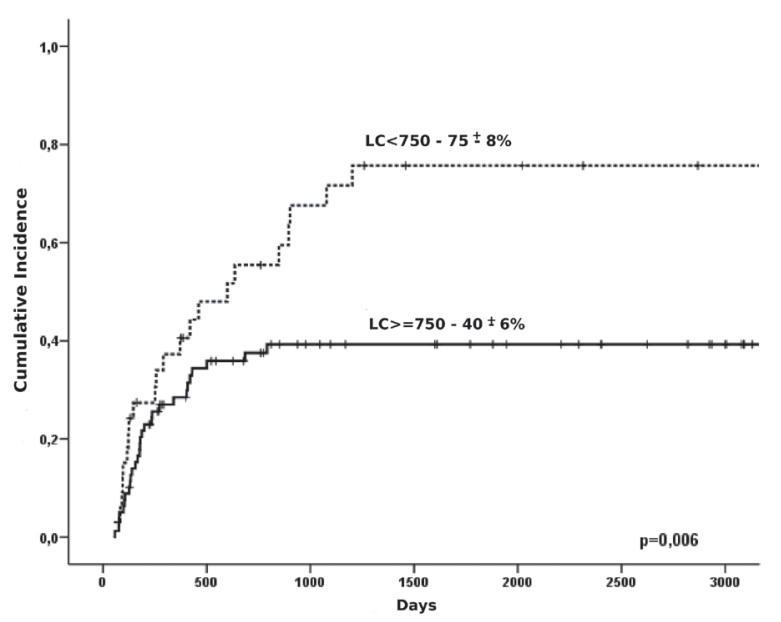

Figure 8 - Cumulative incidence of relapse based on lymphocyte recovery on Day +100

\section{Discussion}

Data analysis shows that it is possible to obtain good survival rates in patients transplanted in the early stage of leukemia and that the main factor related to patient survival is the disease status at the time of HSCT. Patients transplanted in an early stage of the disease had a better overall survival (61\% vs. $27 \%$ in 3 years); this data is similar to the published literature ${ }^{(13,14)}$.

An early LR has been described as an important factor related to disease relapse in acute leukemia patients ${ }^{(7,8)}$. However, in this study significant differences in relapse were not observed between groups. It is believed that some confounding factors may be related to this different result as this is a retrospective study, with great sample variability, including patients transplanted at different times and using different techniques.

It was observed that the patients who presented inadequate LR on Day +30 evolved with worse OS and RFS. This data is compatible with what has been observed in previous studies ${ }^{(7,8,10)}$.

Patients with inadequate LR on Day +30 presented worse RFS, however, no significant difference in the incidence of relapse was observed. This can be explained by the fact that early deaths, that occurred more frequently in the group with inadequate LR on Day +30 , were included in the RFS analysis.

Previous studies report a higher TRM in inadequate LR patients ${ }^{(7,9)}$. This study correlates this data, as a significantly higher incidence of TRM occurred in patients with inadequate LR on Day +30 . This higher incidence of TRM is probably related to the higher vulnerability of the group with inadequate LR since, at this stage, some patients still do not have complete engraftment and have significant immune deficiency. The main cause of death in patients with TRM was infection.

On analyzing the LR on Day +100 , significantly higher OS and RFS are seen in patients with lymphocyte counts $\geq 0.75 \times 10^{9} / \mathrm{L}$ besides a lower cumulative relapse rate. This shows the importance of adequate LR in the initial period after HSCT.

It is known that the most commonly used method to evaluate immune recovery after HSCT is through immunophenotyping; 
the role of $\mathrm{CD}^{+}$and $\mathrm{NK}$ cell recovery is well known in the occurrence of relapse, mortality and infections ${ }^{(15)}$.

Considering that the patients present $\mathrm{NK}$ cell recovery within the first 30 days after $\mathrm{HSCT}^{(5,16)}$ and $\mathrm{CD}^{+}$lymphocyte recover in around 2 or 3 months after HSCT, it can be assumed that patients who did not have adequate LR on Day +100 did not have adequate recovery of these cells. However, a parallel evaluation of the lymphocyte count and immunophenotyping of the peripheral blood would be necessary to prove this hypothesis.

To better evaluate the influence of LR on the relapse and survival of patients, a prospective evaluation of a more homogenous group with parallel analysis of the LR through immunophenotyping would be necessary. However, the findings of the current study serve as a warning to pay more attention to patients with inadequate LR on Days +30 and +100 after HSCT.

\section{Conclusions}

An analysis of LR may be useful to predict OS and RFS after HSCT, however the evaluation of the LR on Day +30 was not a good predictor of relapse after HSCT.

The TRM was significantly higher in patients with inadequate LR $\left(<0.3 \times 10^{9} / \mathrm{L}\right)$ on Day +30 after HSCT.

Regarding the LR on Day +100 after HSCT, there was a higher cumulative incidence of relapse and lower OS and RFS in patients with inadequate LR $\left(<0.75 \times 10^{9} / \mathrm{L}\right)$.

\section{References}

1. Pizzo PA, Poplack DG. Principles and practice of pediatric oncology. $5^{\text {th }}$ ed. Philadelphia: Lippincott Williams \& Wilkins; 2006.

2. Pui CH, Evans WE. Acute lymphoblastic leukemia. N Engl J Med. 1998;339(9):605-15.

3. Thomas ED, Blume KG, Forman SJ. Hematopoietic cell transplantation. $3^{\text {rd }}$ ed. Boston: Blackwell Science; 2004.

4. Davies SM, Rowe JM, Appelbaum FR. Indications for hematopoietic cell transplantation in acute leukemia. Biol Blood Marrow Transplant. 2008;14(1 Suppl 1):154-64. Erratum in: Biol Blood Marrow Transplant. 2008;14(11):1317-8
5. Fry TJ, Mackall CL. Immune reconstitution following hematopoietic progenitor transplantation: challenges for the future. Bone Marrow Transplant. 2005;35(Suppl 1):S53-7.

6. Shilling HG, McQueen KL, Cheng NW, Shizuru JA, Negrin RS, Parham P. Reconstitution of NK cell receptor repertoire following HLA-matched hematopoietic cell transplantation. Blood. 2003;101(9):3730-40.

7. Savani BN, Mielke S, Rezvani K, Montero A, Yong AS, Wish L, et al. Absolute lymphocyte count on day 30 is a surrogate for robust hematopoietic recovery and strongly predicts outcome after $\mathrm{T}$ cell-depleted allogeneic stem cell transplantation. Biol Blood Marrow Transplant. 2007;13(10):1216-23.

8. Kim DH, Kim JG, Sohn SK, Sung WJ, Suh JS, Lee KS, et al. Clinical impact of early absolute lymphocyte count after allogeneic stem cell transplantation. Br J Haematol. 2004;125(2):217-24.

9. Ishaqi MK, Afzal S, Dupuis A, Doyle J, Gassas A. Early lymphocyte recovery post-allogeneic hematopoietic stem cell transplantation is associated with significant graft-versus-leukemia effect without increase in graft-versus-host disease in pediatric acute lymphoblastic leukemia. Bone Marrow Transplant. 2008;41(3):245-52.

10. Flowers ME, Kansu E, Sullivan KM. Pathophysiology and treatment of graft-versus-host disease. Hematol Oncol Clin North Am. 1999;13(5):1091-112, viii-ix.

11. Shulman HM, Sullivan KM, Weiden PL, McDonald GB, Striker GE, Sale GE, et al. Chronic graft versus host syndrome in man. A long term clinicopathologic study of 20 Seattle patients. Am J Med. 1980;69(2):204-17.

12. Mehta PA, Davies SM. Allogeneic transplantation for childhood ALL. Bone Marrow Transplant. 2008;41(2):133-9.

13. Lodewick T, Cornelissen JJ. Allogeneic stem cell transplantation in acute myeloid leukemia: a risk-adapted approach. Blood Rev. 2008;22(6):293-302.

14. Kumar S, Chen MG, Gastineau DA, Gertz MA, Inwards DJ, Lacy MQ, et al. Effect of slow lymphocyte recovery and type of graft-versushost disease prophylaxis on relapse after allogeneic bone marrow transplantation for acute myelogenous leukemia. Bone Marrow Transplant. 2001;28(10):951-6.

15. Koehl, U. Bochennek K, Zimmermann SY, Lehrnbecher T, Sörensen $\mathrm{J}$, Esser R, et al. Immune recovery in children undergoing allogeneic stem cell transplantation: absolute $\mathrm{CD} 8+\mathrm{CD} 3+$ count reconstitution is associated with survival. Bone Marrow Transplant. 2007;39(5):269-78.

16. Kalwak K, Gorczynska E, Toporski J, Turkiewicz D, Slociak M, Ussowicz M, Latos-Grazynska E, et al. Immune reconstitution after haematopoietic cell transplantation in children: immunophenotype analysis with regard to factors affecting the speed of recovery. Br J Haematol. 2002;118(1):74-89 